\title{
The Effects of Corporate Social Marketing on Brand Trust and Purchase Intention
}

\author{
Fei Fu \\ School of Pharmacy \\ Jilin Medical University \\ Jilin, China \\ School of Business Administration \\ Shenyang Pharmaceutical University \\ Shenyang, China
}

\author{
Liang Fan \\ School of Pharmacy \\ Jilin Medical University \\ Jilin, China
}

\author{
Bo Feng* \\ School of Pharmacy \\ Jilin Medical University \\ Jilin, China \\ *Corresponding Author
}

\begin{abstract}
By using a structural equation model (SEM), this paper explores the influence of public welfare marketing of medicine (PWMM) on brand trust (BT) and PI of consumers. The enduring involvement of consumers and the fitting degree of public welfare event in PWMM marketing activity exerts a great influence on the establishment of BT. Meanwhile, BT brought about by the PWMM is proven to improve the purchase intension of consumers. Therefore, pharmaceutical enterprises are supposed to realize the importance of PWMM. They are suggested to establish favorable brand images and word-of-mouth by conducting PWMM activities so as to strengthen consumers' trust in the brands and simulate their purchase intension. Thus, competitive advantages can be formed.
\end{abstract}

Keywords-corporate social marketing; brand trust; purchase intention

\section{INTRODUCTION}

PWMM is not only a form of charity that pharmaceutical enterprises initiatively undertake social responsibility, but also gradually develops to be an important way to set up the charitable images of enterprise. In China, there are various PWMM activities. For instance, the Coca-Cola Co., Ltd and the Chinese Foundation for Prevention of STD and AIDs cooperated to start a propaganda and education project of AIDs prevention; the Accenture Management Consulting Company constructed health and rehabilitation centers for pupils and children, and visits orphans and disabled children on a regular basis. Studies show that when enterprises are marketing under the banner of public welfare, their products are supposed to be more trusted by consumers. However, the current studies mainly are performed from the perspective of enterprises, while rarely concern consumers. In addition, most of the studies focus on case analysis and concern little on theory study [1]. Therefore, this paper establishes a theoretical model for the influence of PWMM on BT and purchase intention (PI) in terms of consumers. Based on the developed scales in other countries, a scale with Chinese characteristics is formed and used to investigate the influence of PWMM on BT and PI of consumers between these factors by using empirical approaches.

\section{THEORETICAL DEVELOPMENT}

\section{A. Corporate Social Marketing}

In 1971, Kotler and Zaltman proposed the concept of social marketing, referring to "the design, implementation, and control of programs calculated to influence the acceptability of social ideas". This concept has received immense attention from researchers in marketing and other disciplines and has been used to assess the effectiveness of interventions designed to influence one's voluntary behavior related to areas such as health, community involvement, injury prevention, and environmental protection involvement, injury prevention, and environmental protection [2-4].

\section{B. The Fitting Degree Between Medicine Brand and Public Welfare Events}

As an important factor influencing the effect of PWMM, the fitting degree refers to the perception of consumers to the matching degree between the public welfare event and the brand. Existing studies present that consumers are more likely to prefer and accept the products with high fitting degree. In addition, consumers consider that pharmaceutical enterprises should sponsor the events related to medical treatment, sanitation and human health [5]. 


\section{Consumer Involvement}

Consumer involvement is defined as that consumers judge the correlation degree between the products or events and themselves from the perspective of their requirements, values and interests. The involvement of product is mainly classified into situation involvement and enduring involvement. The former refers to the involvement with short time in special situations such as when purchasing, while the latter means that in long-term using process. This paper focuses on the enduring involvement of consumers for medicine products. The higher the involvement of products, with the increase of involvement, the more intensive the attention of consumers to the attribute information of products.

\section{BT and PI}

BT is the sense of security that consumers are obtained from a brand under a dangerous environment according to definition of Jose and Elena. It is the confidence expectation for the reliability and purchase trend of a brand product that can satisfy consumers' expectation [1]. It is the confidence and expectation perceived by consumers to the brand. In addition, on the one hand, this definition emphasizes the precondition as that only in dangerous situation, the problems whether consumers trust a brand or not present. On the other hand, it also points out a positive judgment whether brands can live up to the expectation of the consumers. Schiffman and Kanuk once indicated that the PI presents the possibility whether consumers purchase one certain product or not and it mainly involves the PIs based on consumer attitude, perceived value maximization and perceived risk minimization [6].

\section{METHODOLOGY}

\section{A. Conceptual Model and Hypothesis}

When consumers are enough capable of processing information, they are prone to obtain information by using central route to persuasion. The factors influencing BT are the information and involvement of PWMM activities. While consumers are incapable of processing capacity of public welfare activities information, peripheral route is supposed to be utilized to acquire information. At this moment, the fitting degree can exert significant influence on BT. According to the decision-making modes of consumers, the confidence in the consumers' black box is the key factor directly influencing the PIs of consumers. On this basis, a conceptual model is established in this paper, as shown in Figure. Moreover, following assumptions are presented.

$\mathrm{H} 0$ presents that the enduring involvement of consumers to $\mathrm{PWMM}$ has positive influence on $\mathrm{BT}$;

H1 suggests that the situation involvement of consumers to PWMM exerts positive influence on BT;

$\mathrm{H} 2$ shows that the fitting degree between medicine brand and events has a positive influence on BT;

H3 indicates that BT positively affects the PI of consumers.

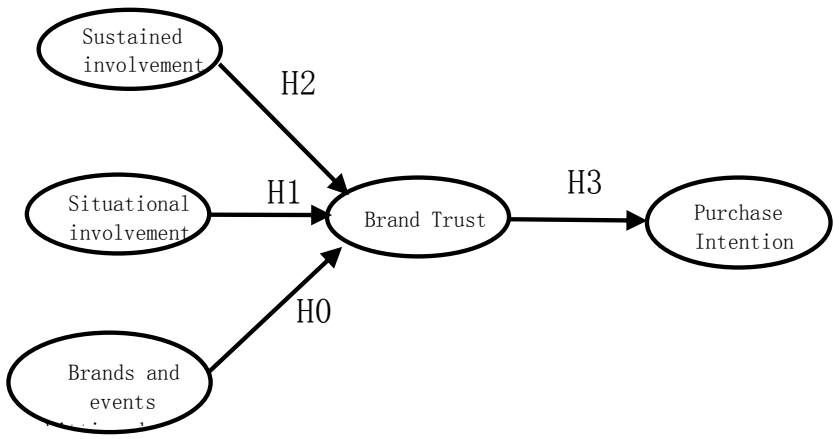

Fig. 1. Research Model

\section{B. Questionnaire Design}

To ensure the reliability and validity of the scale in favorable level, a modified scale is acquired by learning the scales used by scholars in other countries. Thereinto, the factors relating to the enduring involvement (SIa) are as follows: firstly, you are interested in the activity "Merck for Mother" by the Merck and Co. (X1); secondly, you think this activity is important (X2); thirdly, you like the reports which are similar to this activity (X3). While the situation involvement (SIb) includes the following factors: firstly, you think this activity presents positive significance (X4); secondly, you consider this activity is successful (X5); thirdly, you believe this activity is a good idea (X6). In addition, the fitting degree (BEFD) between the brand and the event includes three measuring indexes: the activity "Merck for Mother" by the Merck and Co. is suitable (X7); the "Merck for Mother" is connected with the Merck and Co. (X8); the Merck and Co. is related to the "Merck for Mother"(X9).

BT involves the following eight measuring indexes: the Merck and Co. brand does not let me down (Y1); this brand satisfy my expectation (Y2); I am confident of this brand (Y3); I am pleased with this brand (Y4); this brand can sincerely treat the things I care about (Y5); I can trust that this brand can solve the product problems in the application (Y6); this brand has lived up to my expectation to the products (Y7) and this brand would compensate me if there were any problems (Y8). While PT contains three measuring indexes: firstly, you will recommend this brand to others (Y9); secondly, you would like to purchase the products of this brand (Y10); thirdly, you are willing to purchase the products of this brand once again (Y11). In this paper, the Likert seven-point scale is served as the measuring index of the conceptual model.

\section{Data Collection}

By dispatching questionnaires on the Sojump platform, netizens filled in these questionnaires according to their feelings to the socially useful activity "Merck for Mother" by the Merck Pharmaceutical Co., Ltd. The basic information of participators is shown in Table 1 . Totally 300 questionnaires were handed out, among which, 235 completely filled questionnaires were took back, the effective rate is $78.33 \%$. 
TABLE I.

DEMOGRAPHIC CHARACTERISTICS OF PARTICIPATES IN THE SURVEY

\begin{tabular}{|l|l|l|l|}
\hline Demographic Variables & Variable Attributes & Number & \multicolumn{1}{|c|}{ Ratio } \\
\hline \multirow{4}{*}{ Gender } & Male & 99 & $42.13 \%$ \\
\cline { 2 - 4 } & Female & 136 & $57.87 \%$ \\
\hline \multirow{5}{*}{ Age } & $15-25$ & 164 & $69.79 \%$ \\
\cline { 2 - 4 } & $26-35$ & 56 & $23.83 \%$ \\
\cline { 2 - 4 } & $36-45$ & 12 & $5.11 \%$ \\
\cline { 2 - 4 } & $46-60$ & 3 & $1.28 \%$ \\
\cline { 2 - 4 } & More than 60 & 0 & $0 \%$ \\
\hline \multirow{5}{*}{ Education } & below Bachelor & 18 & $7.66 \%$ \\
\cline { 2 - 4 } & Bachelor & 161 & $68.51 \%$ \\
\cline { 2 - 4 } & Master degree or higher 56 & $23.83 \%$ \\
\hline
\end{tabular}

As shown in the table, there are 99 men participating in this questionnaire survey, accounting for $42.13 \%$, while there are 136 women which occupy $57.87 \%$. Thus it can be seen that fewer men take part in this survey than women. The young aged from 15 to 25 take up $69.79 \%$ at maximum. In addition, there are $68.51 \%$ of people surveyed with undergraduate degree, $7.66 \%$ below undergraduate degree while $23.85 \%$ with master's degree.

\section{DATA ANALYSIS}

\section{A. Reliability and Validity}

Reliability analysis is to check the consensus degree of same one object after repeated measurements: the internal consistency of the measured variable [7]. In this paper, reliability analysis is conducted according to the Cronbach's $\alpha$ coefficient. The larger the Cronbach's $\alpha$ coefficient, the higher the reliability is. That is, the measured variable presents a favorable internal consistency. After the reliability analysis using the statistical software SPSS19.0, the reliability data obtained in each dimension in this questionnaire are demonstrated in Table 2. The values of Cronbach's $\alpha$ all exceed 0.80 . The whole reliability of this questionnaire is 0.966 which is proved to be ideal.

TABLE II. ThE VALUES OF CRONBACH'S $\alpha$ OF EACH SCALE

\begin{tabular}{|l|l|l|}
\hline \multicolumn{1}{|c|}{ Dimension } & Numbers of items & $\begin{array}{c}\text { Values of } \\
\text { Cronbach's } \boldsymbol{\alpha}\end{array}$ \\
\hline Involvement & 6 & 0.855 \\
\hline $\begin{array}{l}\text { Fitting degree between the brand and } \\
\text { the event }\end{array}$ & 3 & 0.873 \\
\hline Consumers' BT & 8 & 0.969 \\
\hline PI & 3 & 0.973 \\
\hline
\end{tabular}

By using the confirmatory factor analysis of software LISREL8.70, the convergent and discriminative validities are verified. The acquired results are illustrated in Figure 2. As can be seen, the convergent validities of each scale and the discriminative validity in each dimension are higher. In addition, the factor loadings are all over 0.5 , which satisfying the requirements of the research.

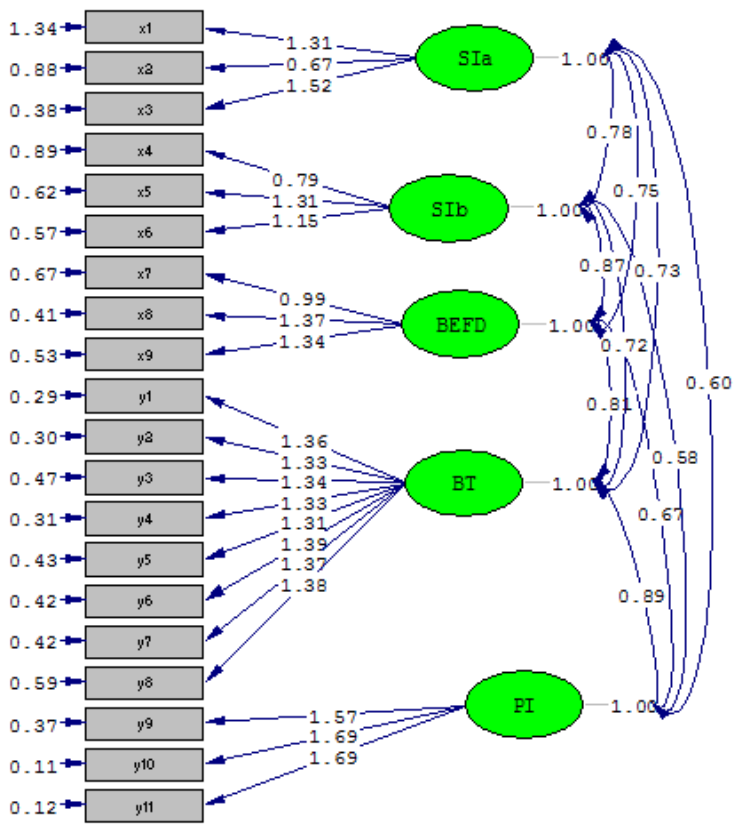

Fig. 2. The results of confirmatory factor analysis

Based on the above results, the modified scale presents ideal reliability and validity. Moreover, the obtained data obtained by using this scale indicate higher consistency. All these conform to the standards of our investigation.

\section{B. Structural Model}

This paper aims to investigate the relationship between three variables including the fitting degree between PWMM brands and events, the involvement of consumers and the BT and PI of consumers as well as the interrelation of these variables. SEM is more beneficial to study multi-factors with multi-structures. Then, by calculating the indexes of the factor loading, whole fitting degree (GFI) in each dimension, it is found that except from the unsatisfactory path coefficient ( $\mathrm{T}$ value of -0.52 , less than 1.96) of the situation involvement to the BT, the fitting degree, GFI and fitting degree of structure of other paths are all favorable. The path coefficients of the modified structural equation model are presented in Figure 3. 


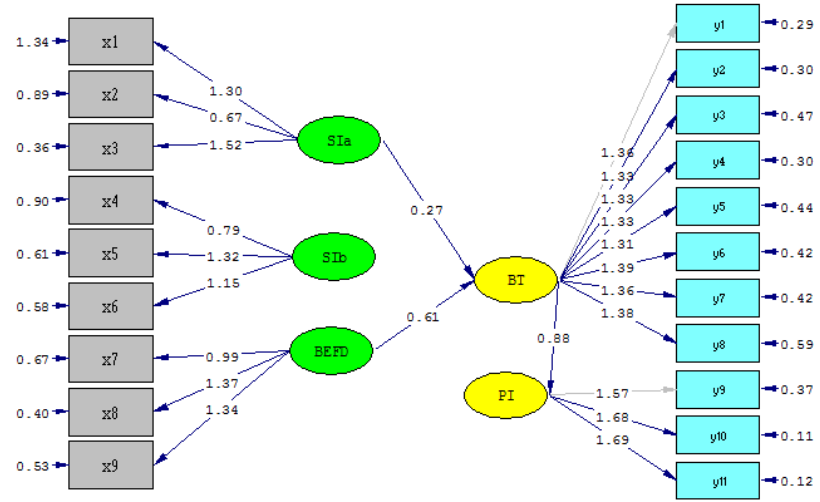

Fig. 3. Coefficients of modified paths

After modified the model, the corresponding indexes of the fitting degrees are shown in Table 3. As shown in the table, the NC value is 3.53 which does not fall within the ideal range of 1-3. This is possibly because the model is complex. As this value is smaller than 5 , it is acceptable. In addition, as the RMSEA value lies between 0.05 and 0.08 , it is reasonable. The other three values including $\mathrm{P}$, GFI and NFI accord with the standard of fitting. Therefore, comprehensive analysis of these five indexes shows that the modified model is reasonably constructed and applicable for this study.

TABLE III. INDEXES OF THE FITTING DEGREES OF THE EVALUATION MODEL

\begin{tabular}{|l|l|l|}
\hline \multicolumn{1}{|c|}{ Statistical test quantity } & $\begin{array}{c}\text { Check } \\
\text { value }\end{array}$ & $\begin{array}{l}\text { Standard or critical value of } \\
\text { fitting }\end{array}$ \\
\hline NC value $(\chi 2 / D F)$ & 3.53 & $\begin{array}{l}\text { NC }>3, \text { the model needs to be } \\
\text { modified }\end{array}$ \\
\hline P value (significance level) & 0 & $<0.1$ \\
\hline GFI value (goodness-of-fit index) & 0.92 & $>0.90$ \\
\hline $\begin{array}{l}\text { RMSEA value (approximate root } \\
\text { mean square residual) }\end{array}$ & 0.07 & $\begin{array}{l}<0.05(\text { well fitted) } \\
0.08(\text { reasonably fitted) }\end{array}$ \\
\hline NFI value (normed fit index) & 0.96 & $>0.90$ \\
\hline
\end{tabular}

\section{Research Hypothesis Verification}

TABLE IV. VERIFICATION OF THE ASSUMPTIONS IN THE STUDY $(\mathrm{H} 0 \sim \mathrm{H} 2)$

\begin{tabular}{|l|l|l|l|}
\hline \multicolumn{1}{|c|}{ Assumptions in the study } & \multicolumn{1}{|c|}{$\begin{array}{c}\text { Completely } \\
\text { standardized } \\
\text { estimates }\end{array}$} & T value & Conclusions \\
\hline $\begin{array}{l}\text { H0: the enduring involvement of } \\
\text { consumers to PWMM has } \\
\text { positive influence on the BT }\end{array}$ & 0.27 & 2.90 & Tenable \\
\hline $\begin{array}{l}\text { H1: the situation involvement of } \\
\text { consumers to PWMM exerts } \\
\text { positive influence on BT }\end{array}$ & Path canceled & $\begin{array}{l}\text { Path } \\
\text { canceled }\end{array}$ & $\begin{array}{l}\text { Path } \\
\text { canceled }\end{array}$ \\
\hline $\begin{array}{l}\text { H2: the fitting degree between } \\
\text { medicine brand and events has a } \\
\text { positive impact on BT }\end{array}$ & 0.61 & 6.73 & Tenable \\
\hline $\begin{array}{l}\text { H3: BT positively affects PI of } \\
\text { consumers }\end{array}$ & 0.88 & 16.18 & Tenable \\
\hline
\end{tabular}

\section{CONCLUSION AND IMPLICATIONS}

\section{A. Conclusion}

From the perspective of consumers, this paper studies the influence of PWMM on the BT and PI of consumers. The following conclusions are drawn:

1) The enduring involvement of consumers to the PWMM activities exerts great influence on the establishment of BT.

In this paper, the enduring involvement of consumers to PWMM is assumed to have positive influence on BT (H0). After calculation, the path coefficient is obtained to be 0.27 and the $\mathrm{T}$ value is 2.85 which is more than 1.96 , thus this assumption is tenable. When consumers perceive that PWMM activities provides important social benefit, or they actively take social responsibility, or socially useful activities are closely related to consumers, they are expected to be more confident of this brand.

2) Compared with the involvement, the fitting degree between the brand and event has a larger impact on BT.

In the plan of PWMM activities, more attention has to be paid to the matching degree between the activities and medicine brand. $\mathrm{H} 2$ shows that the fitting degree between medicine brand and events has a positive influence on BT. This survey indicates that the BT path coefficient of the fitting degree to the brand is 0.61 and its $\mathrm{T}$ value is 6.73 which is more than 1.96. Therefore, the assumption $\mathrm{H} 2$ is true. That is, the higher the matching degree between the perceived medicine activity and a brand, the more confidence of consumers on the brand. Because the higher matching degree presents less suspicion of consumers to the purpose of the medicine marketing activity, thus improving the trust in the medicine brand.

3) BT resulted from the PWMM can improve the PI of consumers.

The BT path coefficient to the PI of consumers is 0.88 and its $\mathrm{T}$ value is 16.18 (larger than 1.96). Therefore, the assumption $\mathrm{H} 3$ is valid. The degree of consumers' BT is supposed to transfer to the possibility of purchasing this brand product.

\section{B. Implications}

Pharmaceutical enterprises are supposed to enrich their understanding to the importance of PWMM. In addition, they are suggested to carry on PWMM activities to establish favorable brand image and word-of-mouth so as to strengthen consumers' trust in their brands and simulate their PIs. As a result, they can obtain different competitive advantages. Therefore, taking PWMM as the long-term investment of pharmaceutical enterprises is an effective way to improve their soft power.

When performing public welfare activities, pharmaceutical enterprises are supposed to pay attention to the activity contents and modes. They should choose the activities that consumers identify and enthusiastically 
participate in. Moreover, these events should be directly related to the products and brand culture.

As PWMM costs long time and needs planned investment, before formulating the marketing strategy, pharmaceutical enterprises have to realize that PWMM is not equivalent to an activity or a donation. On the contrary, it should be a long-term strategic behavior. Meanwhile, PWMM is not a way to obtain social wealth. Therefore, only through persistent activities can the long-term recognition of consumers to the enterprise be acquired.

\section{Limitations and Future Directions}

This study only adopts the samples from the questionnaire survey on the internet with simple sampling method. The investigated objects are relatively young people with high academic credentials. Therefore, to a certain degree, the survey results are less extensive. Though there are many ways to carry out PWMM activities, merely one common way is used in this paper to do the survey. Accordingly, whether or not there are differences in BT degrees of consumers to different marketing methods remains unknown. Thus, further studies need to be conducted to compare the influence of different kinds of PWMM activities so as to provide reference for enterprises to select marketing modes.

\section{REFERENCES}

[1] H. Aizhong. The influence of public welfare marketing on consumer brand trust and purchase intention. Journal of Beijing Technology and Business University (SOCIAL SCIENCE EDITION), vol. 24(3), pp.31-36,2009.

[2] P.Kotler, G. Zaltman, "Social marketing: An approach to planned social change," in Journal of Marketing, vol.35, 1971, pp. 3-12.

[3] A. R.Andreasen, "A social marketing approach to changing mental health practices directed at youth and adolescents," in Health Marketing Quarterly, vol.21(4), 2004 , pp. 51-75.

[4] P. Kotler, N. Roberto, N. Lee, Social marketing: Improving the quality of life, 2nd ed., Thousand Oaks, CA: SAGE. 2002, pp.271279.

[5] W.John, G.Pracejus, D.ouglas, "Olsen.The role of brand/cause fit in the effectiveness of cause-related marketing campaigns," Journal of Business Research, vol. 57, pp. 635-640, 2004.

[6] M,Xue, Research on brand purchase intention of consumers' own brand based on brand trust, Dalian Liaoning: Academic Dongbei University of Finance and Economics, 2010.

[7] W, Fengchao. Research on the influence mechanism of public welfare marketing of beverage enterprises on consumer brand loyalty. Zhejiang. : Zhejiang business University, 2011. 